\title{
Regression Analysis Following Levenberg - Marquardt Algorithm to Estimate Elastic Modulus of Sandy Clay Embankment
}

\author{
Tuan Anh Nguyen ${ }^{1, *}$, Chieu Quang Phan ${ }^{2}$ \\ ${ }^{1}$ Faculty of Transportation Engineering, Ho Chi Minh City University of Transport, Ho Chi Minh City, Vietnam \\ ${ }^{2}$ Faculty of Civil Engineering, Tien Giang University, My Tho City, Tien Giang Province, Vietnam
}

Received March 9, 2021; Revised April 20, 2021; Accepted May 23, 2021

\section{Cite This Paper in the following Citation Styles}

(a): [1] Tuan Anh Nguyen, Chieu Quang Phan, "Regression Analysis Following Levenberg - Marquardt Algorithm to Estimate Elastic Modulus of Sandy Clay Embankment," Civil Engineering and Architecture, Vol. 9, No. 3, pp. 842 - 852, 2021. DOI: 10.13189/cea.2021.090326.

(b): Tuan Anh Nguyen, Chieu Quang Phan (2021). Regression Analysis Following Levenberg - Marquardt Algorithm to Estimate Elastic Modulus of Sandy Clay Embankment. Civil Engineering and Architecture, 9(3), 842 - 852. DOI: 10.13189/cea.2021.090326.

Copyright $\bigcirc 2021$ by authors, all rights reserved. Authors agree that this article remains permanently open access under the terms of the Creative Commons Attribution License 4.0 International License

\begin{abstract}
Road design must consider the factors affecting the elastic modulus of the cohesive soil used for the roadbed. Accurate determination of the elastic modulus of the pavement will help calculate properly the deformation of the pavement and prevent the appearance of cracks in the pavement; especially when the roadbed is flooded. This study is based on the laboratory data, using Levenberg-Marquardt algorithm and building a program for regression analysis, proposing the coefficients to estimate the elastic modulus of the roadbed. From the research results obtained, the way to choose the adjustment coefficients has been improved by adding the coefficient $\mu$, the Levenberg-Marquardt algorithm has solved the problem with only 1,351 iterations, proving the simplicity and efficiency to solve the problem of nonlinear minimum squares that sometimes cannot be solved by the Gauss-Newton method. This algorithm is applied to regression analysis of experimental results, adding the values of coefficients $a_{9}$ and $a_{10}$ to propose the values of the remaining coefficients $a_{n}$ and $b_{n}$ of the formula Dong-Gyou Kim, MS, 2004 with correlation coefficient $\mathrm{R}^{2}$ is 0.8929. As a result, the article proposes the appropriate value of the regression coefficients into the formula to estimate the elastic modulus of the sandy clay embankment according to the humidity and material characteristics of land, instead of using the Benkelman method which is time-consuming, expensive and difficult to implement.
\end{abstract}

Keywords Elastic Modulus, Regression Analysis, Levenberg - Marquardt Algorithm, Roadbed, Moisture

\section{Introduction}

Elastic Modulus (EMS) is determined on the basis of elastic deformation. For road works, EMS is used to calculate the settlement of the foundation and road surface. Due to the immediate nature of the work load, the loading and unloading time is very fast, repeated many times, after a number of times of applied load, the cumulative residual deformation decreases gradually and eliminates, the settlement of the road works depends mainly on the elastic deformation of the roadbed and road surface structure [7].

EMS is defined as the ratio between deviator stress and elastic strain, determined according to the AASHTO T294-94 standard guidelines [1,3,5]. Or EMS can be determined from the point of view of stress as stated by Hicks and Monismith (1971), Uzan (Universal) (1985), Johnson (1986), Rafael Pezo (1993), Louay (1999) $[16,17,29]$.

Some other authors propose the formulas to determine the EMS of the foundation with a linear and nonlinear relationship with the deviator stress. Carmichael and Stuart (1986) proposed the USDA formula, in which soil 
type is the most important factor affecting EMS and the effect of pressure on EMS is also of interest [8]. Although the formula considers the effect of lateral pressure on EMS, the relationship between EMS and deviator stress is linear. In fact, EMS of cohesive soil tends to be nonlinear with deviator stress while keeping lateral pressure. EMS decreases as the plasticity index increases, in fact EMS of cohesive soils increases as the plasticity index increases. The EMS of high ductility cohesive soil ( $\mathrm{CH}$ or $\mathrm{MH})$ is determined to be greater for low plastic soils, which are not practical and therefore limited in application [11-14,33,34].

Drumm et al. (1990) proposed the Hyperbolic formula to determine the EMS of the roadbed, but the effect of lateral pressure on EMS was not considered in this equation [10]. EMS decreases as dry density increases, in fact EMS increases as the dry density of soil increases. The relationship between EMS and deviator stress is nonlinear, but this nonlinear tendency is significantly different from the test results of Kim.MS on soil samples ATH-50-222, 228, 413 type A-6. [21]

Santha (1994) proposed the GDOT formula. In this formula, the stress-strain relationship is nonlinear with many terms, the relationship between EMS and the soil physical characteristics is of interest. However, the formulation has many problems when evaluating the EMS of the roadbed. Only deviator stresses are considered. The effect of lateral pressure is neglected, in fact EMS increases with increased lateral pressure. In fact, EMS increases as the tightness and plasticity index increase, so the coefficients for tightness and plasticity index must be positive but in the above formula is negative [30].

Pezo and Hudson (1994) have proposed the formula TDOT, taking into account the effects of lateral pressure, deviator stress, moisture, density, and date of sample age on the EMS of the cohesive soils. In it, the coefficient that adjusts the EMS value according to the moisture decreases nonlinearly with the increase in humidity, but this formula has a linear relationship and is only applicable to the range of input parameters for this case study [29].

Lee et al, (1995) [22] proposed the formula UCS, which is the simplest formula, considering the influence of the lateral pressure and deviator stress on the EMS value through the coefficient determined by the experiment of triaxial compression test. However, the EMS determined from this formula is highly dependent on the axial stress causing $1 \%$ of the axial strain in the compression test, and in fact EMS is also related to many other basic soil features [22].

The Ohio Department of Transportation proposed an ODOT formula for determining the EMS of the roadbed. This formula does not consider the effects of side and deviator stress, so it is not possible to determine the exact EMS of cohesive soils for a series of soil stress states [28].

This article studies on regression analysis following
Levenberg - Marquardt algorithm to estimate elastic modulus of sandy clay embankment.

\section{Materials and Methods}

\subsection{Regression Equation Identification Basis}

AASHTO T294-94 determines EMS for cohesive soil on the basis of simple linear regression following the formula [2]:

$$
\mathrm{M}_{\mathrm{r}}=\mathrm{k}_{1}\left(\sigma_{\mathrm{d}}\right){ }_{2}^{\mathrm{k}}
$$

Equation (1) only considers the effect of deviator stress and does not consider lateral pressure. Dong-Gyou Kim. MS improves by considering the effect of lateral pressure on EMS. The EMS depends on the ratio of the octahedral stresses to octahedral shear stresses and the coefficients $\mathrm{k}_{1}$, $k_{2}$. The EMS values for the cohesive soil use are estimated in equations (2) and (3).

$$
\begin{gathered}
\frac{M_{r}}{P_{a}}=k_{1}\left[\frac{\frac{\sigma_{o c t}}{P_{a}}}{\left(\frac{\tau_{o c t}}{P_{a}}\right)^{2}}\right]^{k 2} \\
=k_{1}\left[\frac{P_{a} \sigma_{o c t}}{\tau_{o c t}^{2}}\right]^{k 2} \\
=k_{1}\left[\frac{9 P_{a}}{2}\left(\frac{1}{3 \sigma_{d}}+\frac{\sigma_{3}}{\sigma_{d}^{2}}\right)\right]^{k 2}
\end{gathered}
$$

Assuming the two principal stresses $\sigma_{2}$ and $\sigma_{3}$ are equal under the conditions of axial symmetry, Equation (2) becomes Equation (4). Air pressure $\mathrm{Pa}(101 \mathrm{kPa})$ is applied so that the coefficients $\mathrm{k}_{1}$ and $\mathrm{k}_{2}$ are dimensionless.

EMS is dependent on the stress state and basic physical characteristics of the soil. Thus, the coefficients $\mathrm{k}_{1}, \mathrm{k}_{2}$ must contain parameters representing the main stress state and physical characteristics of the soil; The regression coefficients $a_{n}, b_{n}$ in equations (5), (6) show the influence of deviator stress, lateral pressure and major physical characteristics of the soil on EMS. Equation (18) considers the stress state condition of cohesive soil that can actually occur in the roadbed, considering the influence of side pressure and deviator stress.

$\mathrm{k}_{1}, \mathrm{k}_{2}$ : is recognized as equation (5), (6), (7) and (8).

$$
\begin{gathered}
k_{1}=a_{1} a_{3}^{a_{2}}+a_{3}\left(\frac{s}{100}\right)^{a_{4}}+a_{5} q_{u}+a_{6} P I+a_{7}(L L- \\
w)+a_{8}\left(w_{\text {opt }}-w\right)+a_{9}\left(P 200-a_{10}\right) \\
k_{2}=b_{1} \sigma_{3}^{b_{2}}+b_{3}\left(\frac{s}{100}\right)^{b_{4}}+b_{5} q_{u}^{b_{6}}+b_{7} P I+b_{8} L L \\
a_{1}=a_{11}+a_{12}\left(\frac{w_{\text {opt }}-w}{w_{\text {opt }}}\right) \\
b_{1}=b_{11}+b_{12}\left(w-w_{\text {opt }}\right)
\end{gathered}
$$

The coefficients $a_{n}$ and $b_{n}$ in Equation (5), (6), (7) and (8) look up Table 1 and Table 2. 
Table 1. Coefficients of $a_{n}$ for cohesive soils according to the experiment of Kim. MS

\begin{tabular}{|c|c|c|c|}
\hline \multicolumn{5}{|c|}{$\mathrm{k}_{1}$} \\
\hline Cofficient & A-4 & A-6 & A-7-6 \\
\hline $\mathrm{a}_{11}$ & 6.46 & 8.320 & 9.28 \\
\hline $\mathrm{a}_{12}$ & 44.41 & 71.960 & 39.98 \\
\hline $\mathrm{a}_{2}$ & 0.73 & 0.700 & 0.64 \\
\hline $\mathrm{a}_{3}$ & -120.40 & -29.800 & -193.39 \\
\hline $\mathrm{a}_{4}$ & 19.24 & 6.500 & 2.02 \\
\hline $\mathrm{a}_{5}$ & 0.11 & 0.886 & 0.73 \\
\hline $\mathrm{a}_{6}$ & 28.60 & 5.300 & 2.57 \\
\hline $\mathrm{a}_{7}$ & 0.00 & 4.800 & 10.43 \\
\hline $\mathrm{a}_{8}$ & 57.27 & 30.070 & 23.28 \\
\hline $\mathrm{a}_{9}$ & 2.66 & 0.000 & 0.00 \\
\hline $\mathrm{a}_{10}$ & 54.27 & 0.000 & 0.00 \\
\hline
\end{tabular}

Table 2. Coefficients of $b_{n}$ for cohesive soils according to the experiment of Kim. MS

\begin{tabular}{|c|c|c|c|}
\hline \multicolumn{4}{|c|}{$\mathrm{k}_{2}$} \\
\hline Cofficient & $\mathrm{A}-4$ & $\mathrm{~A}-6$ & $\mathrm{~A}-7-6$ \\
\hline $\mathrm{b}_{11}$ & 0.00240 & 0.00753 & 0.01 \\
\hline $\mathrm{b}_{12}$ & 0.00390 & 0.00270 & 0.00 \\
\hline $\mathrm{b}_{2}$ & 0.35100 & 0.52300 & 0.46 \\
\hline $\mathrm{b}_{3}$ & 0.04300 & 0.20500 & 0.08 \\
\hline $\mathrm{b}_{4}$ & 24.00000 & 13.40000 & 15.30 \\
\hline $\mathrm{b}_{5}$ & 3.17000 & 1.13000 & 2.58 \\
\hline $\mathrm{b}_{6}$ & -0.63800 & -0.61200 & -0.60 \\
\hline $\mathrm{b}_{7}$ & -0.00016 & -0.00021 & 0.00 \\
\hline $\mathrm{b}_{8}$ & -0.00028 & -0.00016 & 0.00 \\
\hline
\end{tabular}

The regression coefficients $a_{1}, a_{2}$ in equations (5) and (7) show the effect of the change in humidity value compared with the optimum moisture value and pressure on the EMS, $a_{3}$ and $a_{4}$ values. The influence of saturation on the EMS value, $a_{5}$ the effect of the compressive strength on the EMS value, a6 effect of the plasticity index on the EMS value, $a_{7}$ the effect of the difference in moisture from the liquid limit on the EMS value, $a_{8}$ the effect of the change in moisture value around the optimum moisture value on the EMS, $a_{9}$ and $a_{10}$ values affect the percentage of particles passing through sieve No.200 on the EMS value, through $k_{1}$. The regression coefficients $b_{1}, b_{2}$ in equations (6) and (8) show the effect of the change of $w$ value around the optimum moisture value and pressure on the EMS value, $b_{3}$ and $b_{4}$ influence of saturation on the EMS value, $b_{5}$ and $b_{6}$ affect the influence of the compressive strength on the EMS value, $b_{7}$ the effect of the plasticity on the EMS value, $b_{8}$ the effect of the liquid limit on the EMS value, through $\mathrm{k}_{2}$.

$\mathrm{k}_{1}$ and $\mathrm{k}_{2}$ are established on the basis of the relationship between the stress state, physical characteristics of the soil, and the EMS tested in the laboratory. The coefficients of an and bn in Equation (5), (6) are determined by regression analysis based on the least squares method. Specific values of the coefficients of $a_{n}$ and $b_{n}$ obtained from the experimental results are listed in Table 1 and Table 2.

The physical characteristics and classification of the soil samples studied by Kim. MS are presented in Table 3 . The experimental sample is named by the research project according to the locality, route, and the collection process. [4]

Table 3. Physical characteristics and classification of Kim. MS soil samples

\begin{tabular}{|c|c|c|c|c|c|c|c|}
\hline \multicolumn{2}{|c|}{ Soil type } & \multirow{2}{*}{ Form name } & \multirow{2}{*}{$\begin{array}{l}\text { Liquid limit } \\
(\%)\end{array}$} & \multirow{2}{*}{$\begin{array}{l}\text { Plasticity } \\
\text { index }(\%)\end{array}$} & \multirow{2}{*}{ Sand $(\%)$} & \multirow{2}{*}{ Dust (\%) } & \multirow{2}{*}{ Clay $(\%)$} \\
\hline AASHTO & USCS & & & & & & \\
\hline \multirow{4}{*}{ A-4 } & SC-SM & MUSK-60-21 & 29 & 6 & 29 & 34 & 8 \\
\hline & $\mathrm{CL}$ & GREEN-35-21.13,320,400 & 24 & 8 & 22 & 51 & 13 \\
\hline & $\mathrm{CL}$ & WAS-7-Mari & 29 & 10 & 3 & 46 & 17 \\
\hline & $\mathrm{CL}$ & SHE-SR47 & 26 & 9 & 17 & 66 & 14 \\
\hline \multirow{5}{*}{ A-6 } & $\mathrm{CL}$ & WAR-741-3 & 28 & 11 & 23 & 49 & 12 \\
\hline & $\mathrm{CL}$ & WAS-821-113, 13216 & 32 & 11 & 13 & 55 & 21 \\
\hline & $\mathrm{CL}$ & BEL-SR147, 265 & 35 & 11 & 4 & 72 & 19 \\
\hline & $\mathrm{CL}$ & ATH-50-Cool & 33 & 13 & 8 & 45 & 39 \\
\hline & $\mathrm{CL}$ & ATH-50-222, 228,413 & 31 & 12 & 18 & 42 & 14 \\
\hline \multirow{4}{*}{ A-7-6 } & $\mathrm{CH}$ & ATH-SR7 & 59 & 32 & 0 & 66 & 34 \\
\hline & $\mathrm{CH}$ & FAI-170 & 55 & 36 & 7 & 53 & 39 \\
\hline & $\mathrm{CL}$ & CRAW-Beal & 41 & 21 & 7 & 81 & 12 \\
\hline & CL & HEN-SR6, 24 & 41 & 20 & 5 & 55 & 40 \\
\hline
\end{tabular}


The characteristics of Kim. MS's EMS estimation formula (2) are illustrated in the diagram in Fig. 1. EMS varies with five different stress classes of 14, 28, 41, 55, $69 \mathrm{kPa}$ and three pressure classes. The lateral pressures are $0,21,41 \mathrm{kPa}$ at the $\mathrm{k}_{1}$ value is 1 and $\mathrm{k}_{2}$ is 0.1 . EMS increases as lateral pressure increases and deviator stress decreases. EMS calculated from Equation (4) decreases with a nonlinear trend as deviator stress increases; in accordance with the results of three-axis compression test.

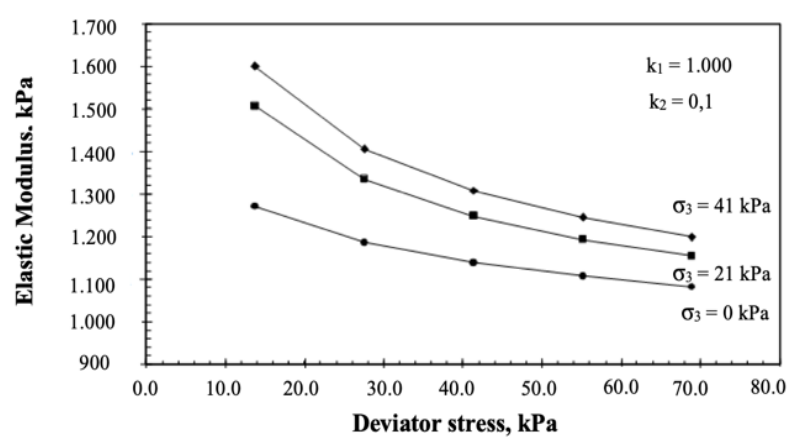

Figure 1. EMS changes with stress and lateral pressure [3]

Fig. 2 illustrates the graph of EMS calculated using Equation (4) at a pressure value of $21 \mathrm{kPa}$ with a coefficient $\mathrm{k}_{1}$ of 100 respectively; 500 and $\mathrm{k}_{2}$ equals 0.1 .

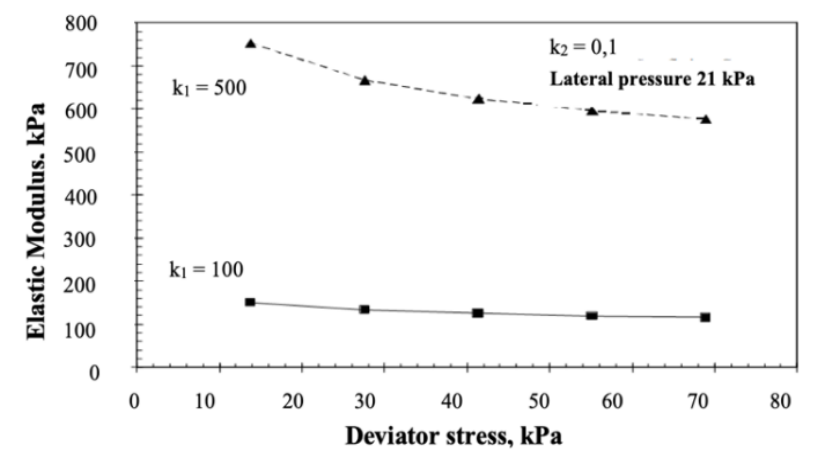

Figure 2. EMS according to deviator stress as the coefficient k1 increases

Keep the same value of lateral pressure and coefficient $k_{2}$, with five grades of deviator stress, as coefficient $k_{1}$ increases, EMS increases. Coefficients $\mathrm{k}_{1}$ increase as lateral pressure, compressive strength, liquid limit, plasticity index, optimum humidity, percentage of soil passing through sieve No.200 increase and saturation and humidity decrease. EMS depends mainly on the coefficient $\mathrm{k}_{1}$.

In Fig. 3, keeping the value of the lateral pressure and the coefficient $\mathrm{k}_{1}$ with five levels of deviator stress, when the coefficient $k_{2}$ increases, EMS increases. Coefficients $\mathrm{k}_{2}$ increase as lateral pressure, flexural strength, loose limit, plasticity index increase and sample saturation decreases. When the coefficient $\mathrm{k}_{2}$ decreases, the EMS decreases linearly with the deviator stress. The EMS value does not depend much on the coefficient $\mathrm{k}_{2}$.

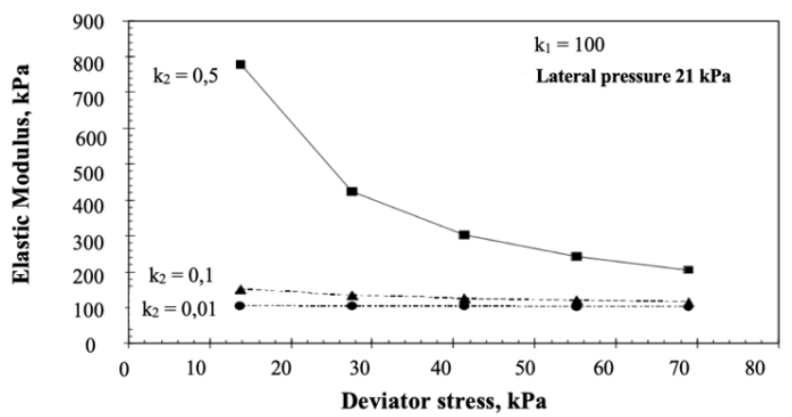

Figure 3. EMS according to deviator stress as the coefficient k2 increases

To evaluate the reliability of formula (4), Kim, MS compared the EMS value estimated by formula (4) with EMS value according to the results of triaxial compression test. The different humidity (in the dry, wet, optimal and saturated branch) of the 13 samples listed in Table 3. Fig. 4 shows the comparison results between EMS according to the results of triaxial compression test in room and estimated EMS calculated using formula (4). Correlation coefficient $R^{2}=0.996$. Accuracy is very reliable.

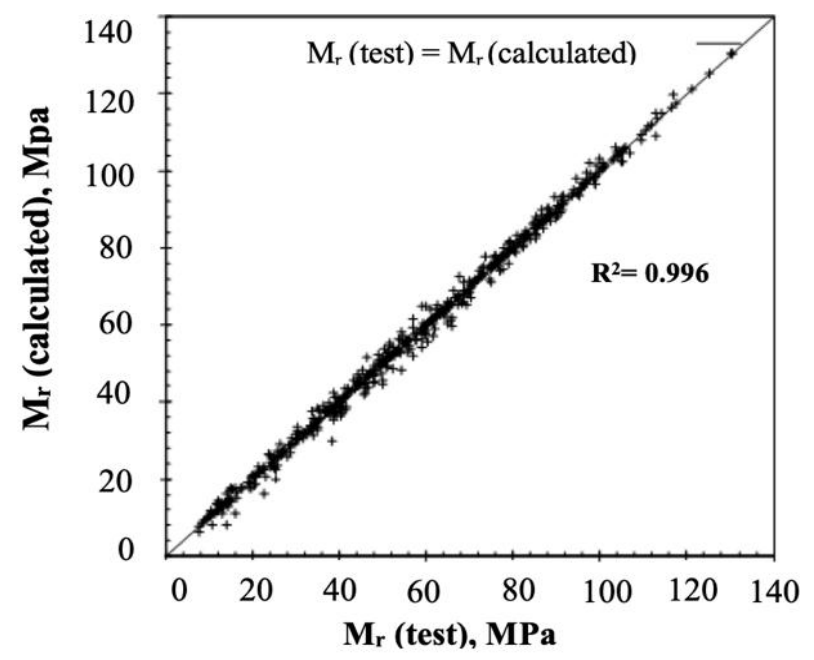

Figure 4. Comparison of $\mathrm{M}_{\mathrm{r}}$ value according to results of tri-axial compression test of 13 samples with formula (4) for all humidity [9].

\subsection{Identify Equation of Regression Analysis}

Soil samples studied by Kim.MS have quite similar mechanical properties with sandy clay samples collected in the annual flood routes in the Mekong Delta. Mechanical and physical characteristics of soil samples type A-6 studied by Kim. MS: liquid limit from $28 \%$ to $35 \%$, plasticity index from $11 \%$ to $13 \%$, sand particle content from $4 \%$ to $23 \%$, dust from $42 \%$ to $72 \%$, clay from $12 \%$ to $39 \%$, optimum humidity from $13 \%$ to $16 \%$, as Table 3. Physical and mechanical characteristics of sandy clay samples collected on annual flood routes in the Mekong Delta: liquid limit from $29 \%$ to $37.6 \%$, plasticity index from $11.3 \%$ to $16.4 \%$, sand particle composition from $5.8 \%$ to $36.8 \%$, dust from $22.9 \%$ to $53.8 \%$, clay 
from $31.2 \%$ to $41 ., 4 \%$, optimum humidity from $14.8 \%$ to $21.2 \%$. Compare the physical properties of the soil samples as shown in Table 4.

Table 4. Comparison of Atterberg limit and grain composition of soil samples

\begin{tabular}{|c|c|c|}
\hline Parameter & Kim. MS & This research \\
\hline Liquid limit (\%) & $28 \div 35$ & $29 \div 38$ \\
\hline Plasticity index (\%) & $11 \div 13$ & $11 \div 16$ \\
\hline Sand (\%) & $4 \div 23$ & $6 \div 37$ \\
\hline Dust (\%) & $42 \div 72$ & $23 \div 54$ \\
\hline Clay (\%) & $12 \div 39$ & $31 \div 41$ \\
\hline
\end{tabular}

Soil samples were tested by Kim.MS with humidity from $10.3 \%$ to $27.2 \%$, the range of changes is relatively wide, suitable for the study of changes in humidity of the flooded roadbed in the Mekong Delta. Formula by Kim. MS gives more accurate results than 6 formulas popular in America. Therefore, the regression analysis to determine the EMS of the sandy clay embankment in the Mekong Delta can choose the formula of Kim. MS (4); with $\mathrm{k}_{1}$ is still calculated according to formula (5), regression coefficients $a_{1}, a_{2}$, consider the influence of lateral pressure; $a_{3}, a_{4}$, consider the influence of saturation; $a_{5}$, considering the impact of compressive strength in the chamber; $\mathrm{a}_{6}$, considering the influence of the plasticity index; $a_{7}$, consider the effect of the difference of moisture on the liquid limit; $a_{8}, a_{11}, a_{12}$, considering the effect of the difference in humidity on the optimum humidity; $\mathrm{a}_{9}, \mathrm{a}_{10}$, taking into account the effect of the No.200 pass-through content on the EMS value; $\mathrm{k}_{2}$ calculated according to the formula (6) regression coefficients $b_{1}, b_{2}$, considering the influence of lateral pressure; $b_{3}, b_{4}$, consider the influence of saturation; $b_{5}, b_{6}$, consider the impact of compressive strength in chamber; $b_{7}$, considering the influence of the plasticity index; $b_{8}$, considering the influence of liquid limit; $b_{11}, b_{12}$, consider the effect of the difference in moisture with the optimum humidity on the EMS value.

In regression analysis, use the equation (4), (5), (6), (7), including 11 regression coefficients: $a_{11}, a_{12}, a_{2}, a_{3}, a_{4}, a_{5}$, $a_{6}, a_{7}, a_{8}, a_{9}, a_{10}$ and 9 regression coefficients: $b_{11}, b_{12}, b_{2}$, $\mathrm{b}_{3}, \mathrm{~b}_{4}, \mathrm{~b}_{5}, \mathrm{~b}_{6}, \mathrm{~b}_{7}, \mathrm{~b}_{8}$.

\subsection{Regression Analysis}

\subsubsection{Data gathering}

Collect the test results to determine the EMS value according to humidity corresponding to three levels of lateral pressure, five levels of deviator stress, particle content of sieve No.200, liquid limit, plasticity index, moisture content, the advantages, saturation and compressive strength of the soil samples.

\subsubsection{Use regression analysis algorithm}

This section presents the algorithm for determining the regression coefficients of the nonlinear formula by the method of least squares [15,18-20,24,25,31].

The least squares problem is defined as follows:

Find $x^{*}$ that the following $\mathrm{F}(\mathrm{x})$ function reaches the minimum value:

$$
F(x)=\frac{1}{2} \sum\left(f_{i}(x)\right)^{2}
$$

In which $\mathrm{f}_{\mathrm{i}}: \mathrm{R}^{\mathrm{n}} \rightarrow \mathrm{R}, \quad \mathrm{i}=1, \ldots, \mathrm{m}$

An important application of the least squares problem is to find formulas based on a given set of data. Example of finding the formula for a set of $\mathrm{m}$ points $(\mathrm{t} 1, \mathrm{y} 1)$, ( $\mathrm{t} 2$, $\mathrm{y} 2), \ldots,\left(\mathrm{t}_{\mathrm{m}}, \mathrm{y}_{\mathrm{m}}\right)$ in Fig. 5. The set of points is approximately equal to the formula:

$$
M(x, t)=x_{3} e^{x_{1} t}+x_{4} e^{x_{2} t}
$$

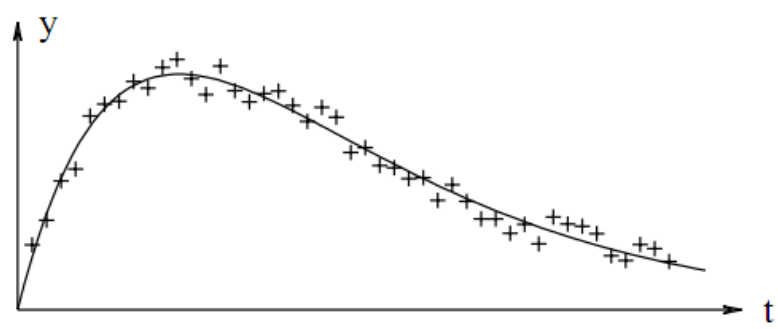

Figure 5. Graph of $M(x, t)$ is a continuous line (The set of points $\left(t_{m}, y_{m}\right)$ is marked as + )

The formula $M(x, t)$ depends on the parameters $x=\left[x_{1}\right.$, $\left.\mathrm{x}_{2}, \mathrm{x}_{3}, \mathrm{x}_{4}\right] \mathrm{T}$. Whatever value of $\mathrm{x}$ we can calculate the remainder:

$$
\begin{gathered}
f_{i}(x)=y_{i}-M\left(x, t_{i)}\right. \\
=y_{i}-x_{3} e^{x_{1} t}+x_{4} e^{x_{2} t}, \mathrm{i}=1, \ldots, \mathrm{m}
\end{gathered}
$$

$\mathrm{F}(\mathrm{x})$ is the sum of the sum of the squares of these remainders. The problem is to find $\mathrm{x}^{*}$ such that $\mathrm{F}(\mathrm{x})$ is the smallest, $\mathrm{x}^{*}$ is the regression coefficients of the formula $\mathrm{M}(\mathrm{x}, \mathrm{t})$. In some cases, $\mathrm{F}(\mathrm{x})$ is also known as the objective function or the cost function.

\subsubsection{Levenberg-Marquardt algorithm}

The least squares problem can be solved by many different methods. This section describes the method for calculating the coefficients $\mathrm{x}^{*}$

Formula (9) can be rewritten as follows:

$F(\mathbf{x})=\frac{1}{2} \sum_{i=1}^{m}\left(f_{i}(\mathbf{x})\right)^{2}=\frac{1}{2}\|\mathbf{f}(\mathbf{x})\|^{2}=\frac{1}{2} \mathbf{f}(\mathbf{x})^{\top} \mathbf{f}(\mathbf{x})$

Assuming $f$ is a continuous function, $f$ can expand the Taylor series as follows:

$$
\mathbf{f}(\mathbf{x}+\mathbf{h})=\mathbf{f}(\mathbf{x})+\mathbf{J}(\mathbf{x}) \mathbf{h}+O\left(\|\mathbf{h}\|^{2}\right)
$$

In which, $\mathrm{J}$ is the Jacobi matrix calculated as follows:

$$
(\mathbf{J}(\mathbf{x}))_{i j}=\frac{\partial f_{i}}{\partial x_{j}}(\mathbf{x})
$$

From (15), the first-order partial derivative of $\mathrm{F}$ would be: 


$$
\frac{\partial F}{\partial x_{j}}(\mathbf{x})=\sum_{i=1}^{m} f_{i}(\mathbf{x}) \frac{\partial f_{i}}{\partial x_{j}}(\mathbf{x}) .
$$

Thus, the gradient of $\mathrm{F}$ is:

$$
\mathbf{F}^{\prime}(\mathbf{x})=\mathbf{J}(\mathbf{x})^{\top} \mathbf{f}(\mathbf{x})
$$

We can calculate Hesse matrix of F. From equation (13), the element in position (j,k) in Hesse matrix would be:

$\frac{\partial^{2} F}{\partial x_{j} \partial x_{k}}(\mathbf{x})=\sum_{i=1}^{m}\left(\frac{\partial f_{i}}{\partial x_{j}}(\mathbf{x}) \frac{\partial f_{i}}{\partial x_{k}}(\mathbf{x})+f_{i}(\mathbf{x}) \frac{\partial^{2} f_{i}}{\partial x_{j} \partial x_{k}}(\mathbf{x})\right)$

Thus:

$$
\mathbf{F}^{\prime \prime}(\mathbf{x})=\mathbf{J}(\mathbf{x})^{\top} \mathbf{J}(\mathbf{x})+\sum_{i=1}^{m} f_{i}(x) \mathbf{f}_{i}^{\prime \prime}(\mathbf{x})
$$

The Gauss-Newton method is based on the linear approximation of the $\mathrm{f}$ function from Taylor expansion $[6,23]$ :

$$
\mathbf{f}(\mathbf{x}+\mathbf{h}) \simeq \ell(\mathbf{h}) \equiv \mathbf{f}(\mathbf{x})+\mathbf{J}(\mathbf{x}) \mathbf{h}
$$

From definition of (9), $\mathrm{F}(\mathrm{x})$ is rewritten as follows:

$$
\begin{aligned}
F(\mathbf{x}+\mathbf{h}) \simeq L(\mathbf{h}) & \equiv \frac{1}{2} \ell(\mathbf{h})^{\top} \ell(\mathbf{h}) \\
& =\frac{1}{2} \mathbf{f}^{\top} \mathbf{f}+\mathbf{h}^{\top} \mathbf{J}^{\top} \mathbf{f}+\frac{1}{2} \mathbf{h}^{\top} \mathbf{J}^{\top} \mathbf{J} \mathbf{h} \\
& =F(\mathbf{x})+\mathbf{h}^{\top} \mathbf{J}^{\top} \mathbf{f}+\frac{1}{2} \mathbf{h}^{\top} \mathbf{J}^{\top} \mathbf{J h}
\end{aligned}
$$

$\mathrm{A}^{\mathrm{T}}$ is the transposition of matrix $\mathrm{A}$, has the following 2 properties:

$$
\begin{gathered}
(\mathrm{A}+\mathrm{B})^{\mathrm{T}}=\mathrm{A}^{\mathrm{T}}+\mathrm{B}^{\mathrm{T}} \text { and }(\mathrm{cA})^{\mathrm{T}}=\mathrm{c}\left(\mathrm{A}^{\mathrm{T}}\right) \\
(\mathrm{AB})^{\mathrm{T}}=\left(\mathrm{B}^{\mathrm{T}}\right)\left(\mathrm{A}^{\mathrm{T}}\right)
\end{gathered}
$$

From formula (13)

$$
F(x)=1 / 2 f(x)^{T} f(x)=1 / 2 f^{T} f
$$

According to Equation (20) then

$$
f(x+h)=f(x)+J(x) h=f+J h
$$

From these 2 expressions calculate $\mathrm{F}(\mathrm{x}+\mathrm{h})$ by replacing (20) in (13).

(The operations are matrix addition, multiplication, and transposition)

$$
\begin{gathered}
F(x+h)=1 / 2 f(x+h)^{T} f(x+h) \\
=1 / 2(f+J h)^{T}(f+J h) \\
=1 / 2\left(f^{T}+(J h)^{T}\right)(f+(J h)) \\
=1 / 2\left(f^{T} f+f^{T}(J h)+(J h)^{T} f+(J h)^{T}(J h)\right) \\
=1 / 2\left(f^{T} f+f^{T}(J h)+h^{T} J^{T} f+h^{T} J^{T} J h\right) \\
=1 / 2\left(f^{T} f+f^{T}(J h)+h^{T} J^{T} f+h^{T} J^{T} J h\right)
\end{gathered}
$$

But: $\left.f^{\mathrm{T}}(\mathrm{Jh})=\mathrm{f}^{\mathrm{T}}(\mathrm{Jh})^{\mathrm{T}}\right)^{\mathrm{T}}=(\mathrm{Jh})^{\mathrm{T}} \mathrm{f}=\mathrm{h}^{\mathrm{T}} \mathbf{J}^{\mathrm{T}} \mathrm{f}$

So:

$$
F(x+h)=1 / 2\left(f^{T} f+h^{T} J^{T} f+h^{T} J^{T} f+h^{T} J^{T} J h\right)
$$

$$
\begin{aligned}
& F(x+h)=1 / 2\left(f^{T} f+2 h^{T} J^{T} f+h^{T} J J h\right) \\
& F(x+h)=1 / 2 f^{T} f+h^{T} J^{T} f+1 / 2 h^{T} J^{T} J h
\end{aligned}
$$

This is the formula (21).

Where $\mathrm{f}=\mathrm{f}(\mathrm{x})$ and $\mathrm{J}=\mathrm{J}(\mathrm{x})$.

The Gauss-Newton repetition step determines $h_{g n}$ such that $\mathrm{L}(\mathrm{h})$ reaches minimum.

It is easy to see that the gradient and Hesse matrix of L are as follows:

$$
\begin{gathered}
\mathrm{L}^{\prime}(\mathrm{h})=\mathrm{J}^{\mathrm{T}} \mathrm{f}+\mathrm{J}^{\mathrm{T}} \mathbf{J h} \\
\mathrm{L}^{\prime}{ }^{\prime}(\mathrm{h})=\mathbf{J}^{\mathrm{T}} \mathbf{J}
\end{gathered}
$$

From (17) and (26), deduce $\mathrm{L}^{\prime}(0)=\mathrm{F}^{\prime}(\mathrm{x})$. Moreover, from (19), L"(h) is independent from $h$, symmetrical and always positive. This leads to $\mathrm{L}(\mathrm{h})$ reaching minimum when $L^{\prime}(h)=0$. The correction coefficients $h_{g n}$ are determined by solving the following system of equations:

$$
\left(\mathrm{J}^{\mathrm{T}} \mathrm{J}\right) \mathrm{h}_{\mathrm{gn}}=-\mathrm{J}^{\mathrm{T}} \mathrm{f}
$$

Equations of (28) can be solved by the Cholesky method [32].

Gauss-Newton algorithm for $\mathrm{x} *$ is presented as follows:

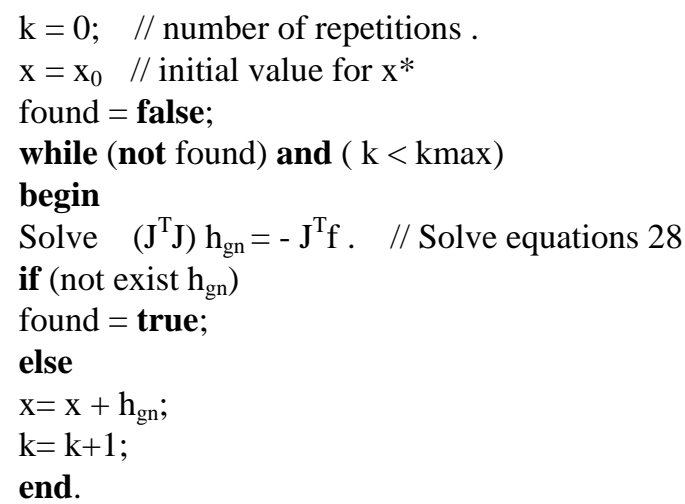

In some cases, the Gauss-Newton Method will fail because $\mathrm{h}_{\mathrm{gn}}$ cannot be found due to rank $(\mathrm{J}(\mathrm{x}))<\mathrm{m}$.

The Levenberg-Marquardt method is based on the Gauss-Newton method, improving the selection of the $h_{l m}$ correction coefficients.

Levenberg-Marquardt added the formula coefficient $\mu$ as follows:

$$
\left(\mathrm{J}^{\mathrm{T}} \mathrm{J}+\mu \mathrm{I}\right) \mathrm{h}_{\mathrm{lm}}=-\mathrm{g}
$$

Where, $\mathrm{J}=\mathrm{J}(\mathrm{x}), \mathrm{f}=\mathrm{f}(\mathrm{x}), \mathrm{g}=-\mathrm{J}^{\mathrm{T}} \mathrm{f}, \mu>0$. I is the unit matrix.

For $\mu$ to be small, hlm is chosen equal to $\mathrm{h}_{\mathrm{gn}}$, in contrast with is large, $\mathrm{h}_{\mathrm{lm}}$ is chosen by the formula:

$$
h_{l m} \cong-\frac{1}{\mu} g=-\frac{1}{\mu} F^{\prime}(x)
$$

The initial value $\mu_{0}$ is chosen as follows:

$$
\mu_{0}=\tau \cdot \max _{i}\left(a_{i i}^{(0)}\right)
$$

For $\mathrm{a}_{\mathrm{ij}}$ belonging to the matrix $\mathrm{A}=\mathrm{J}(\mathrm{x}) \mathrm{T} \mathrm{J}(\mathrm{x})$ and $\tau$ chosen by the user, normally $\tau=10^{-6}$.

During the iteration, the factor $\mu$ can be updated by the 
ratio:

$$
\varrho=\frac{F(x)-F\left(x+h_{l m}\right)}{L(0)-L\left(h_{l m}\right)}
$$

The denominator of this ratio is calculated using the following formula:

$$
\begin{aligned}
L(\mathbf{0})-L\left(\mathbf{h}_{\mathrm{lm}}\right) & =-\mathbf{h}_{\operatorname{lm}}^{\top} \mathbf{J}^{\top} \mathbf{f}-\frac{1}{2} \mathbf{h}_{\operatorname{lm}}^{\top} \mathbf{J}^{\top} \mathbf{J h}_{\mathrm{lm}} \\
& =-\frac{1}{2} \mathbf{h}_{\mathrm{lm}}{ }^{\top}\left(\mathbf{2} \mathbf{g}+\left(\mathbf{J}^{\top} \mathbf{J}+\mu \mathbf{I}-\mu \mathbf{I}\right) \mathbf{h}_{\mathrm{lm}}\right) \\
& =\frac{1}{2} \mathbf{h}_{\mathrm{lm}}{ }^{\top}\left(\mu \mathbf{h}_{\mathrm{lm}}-\mathbf{g}\right) .
\end{aligned}
$$

A larger value $\varrho$ means that $\mathrm{L}\left(\mathrm{h}_{\mathrm{lm}}\right)$ is closer to $\mathrm{F}(\mathrm{x}+$ $\left.\mathrm{h}_{\mathrm{lm}}\right)$, so $\mu$ can be reduced, otherwise, it is small and possibly negative, so $\mu$ must be increased.

The iterations of the Levenberg-Marquardt method will stop when:

+ Reach the minimum global value: $\mathrm{F}^{\prime}\left(\mathrm{x}^{*}\right)=\mathrm{g}\left(\mathrm{x}^{*}\right)=0$, we use the condition:

$$
\|\mathbf{g}\|_{\infty} \leq \varepsilon_{1}
$$

Where $\varepsilon_{1}$ is a positive, very small number chosen by the user.

+ The changeover $\mathrm{x}$ is very small; the following condition is used:

$$
\left\|\mathbf{x}_{\text {new }}-\mathbf{x}\right\| \leq \varepsilon_{2}\left(\|\mathbf{x}\|+\varepsilon_{2}\right)
$$

$\varepsilon_{2}$ is also a positive number and is chosen by the user.

+ Number of iterations reaches limit value $\mathrm{k}_{\max }$ to limit infinite loop.

$$
\mathrm{k} \geq \mathrm{k}_{\max }
$$

$\mathrm{k}_{\max }$ is selected by the user.

The Levenberg-Marquardt algorithm is presented as follows:

$$
\begin{aligned}
& k:=0 ; \quad \nu:=2 ; \quad \mathbf{x}:=\mathbf{x}_{0} \\
& \mathbf{A}:=\mathbf{J}(\mathbf{x})^{\top} \mathbf{J}(\mathbf{x}) ; \quad \mathbf{g}:=\mathbf{J}(\mathbf{x})^{\top} \mathbf{f}(\mathbf{x}) \\
& \text { found }:=\left(\|\mathbf{g}\|_{\infty} \leq \varepsilon_{1}\right) ; \quad \mu:=\tau * \max \left\{a_{i i}\right\} \\
& \text { while (not } \text { found }) \text { and }\left(k<k_{\max }\right) \\
& \text { begin } \\
& k:=k+1 ; \quad \text { Solve }(\mathbf{A}+\mu \mathbf{I}) \mathbf{h}_{\mathrm{lm}}=-\mathbf{g} \\
& \text { if }\left\|\mathbf{h}_{\mathrm{lm}}\right\| \leq \varepsilon_{2}\left(\|\mathbf{x}\|+\varepsilon_{2}\right) \\
& \quad \text { found }:=\text { true } \\
& \text { else } \\
& \quad \mathbf{x}_{\text {new }}:=\mathbf{x}+\mathbf{h}_{\operatorname{lm}} \\
& \varrho:=\left(F(\mathbf{x})-F\left(\mathbf{x}_{\text {new }}\right)\right) /\left(L(\mathbf{0})-L\left(\mathbf{h}_{\mathrm{lm}}\right)\right) \\
& \quad \text { if } \varrho>0 \\
& \quad \mathbf{x}:=\mathbf{x}_{\text {new }} \\
& \quad \mathbf{A}:=\mathbf{J}(\mathbf{x})^{\top} \mathbf{J}(\mathbf{x}) ; \quad \mathbf{g}:=\mathbf{J}(\mathbf{x})^{\top} \mathbf{f}(\mathbf{x}) \\
& \quad \text { found }:=\left(\|\mathbf{g}\|_{\infty} \leq \varepsilon_{1}\right) \\
& \quad \mu:=\mu * \max \left\{\frac{1}{3}, 1-(2 \varrho-1)^{3}\right\} ; \nu:=2 \\
& \quad \text { else } \\
& \quad \mu:=\mu * \nu ; \quad \nu:=2 * \nu \\
& \text { end } \quad
\end{aligned}
$$

This section presented the Levenberg-Marquardt algorithm to determine the regression coefficients $\mathrm{x} *$ for a formula. The execution time of the algorithm depends on the selection of initial values $\mathrm{x} 0$ and input parameters $\tau, \varepsilon_{1}$, $\varepsilon_{2}, \mathrm{k}_{\max }$. In some cases, the algorithm ends with the condition (36), when $\mathrm{k}$ is greater than $\mathrm{k}_{\max }$, it is necessary to review the regression results because then $\mathrm{F}(\mathrm{x})$ has not reached the minimum at $\mathrm{x}_{\mathrm{k}}$. However, the Levenberg-Marquard algorithm is still a good one to solve the nonlinear minima-squared problem.

The Levenberg-Marquard algorithm has improved efficiency to solve non-linear least squares problems. This algorithm can be widely applied in many technical fields needing regression analysis to determine the coefficients of predetermined formulas.

\section{Results and Discussion}

To determine the regression coefficients, use the Levenberg - Marquardt algorithm in the LAPACK library (Linner Algebra Package) and write a program to analyze the regression coefficients using Visual $\mathrm{C}++$ to analyze the regression coefficients for the fomula (4).

Regression coefficient analysis program is performed on the basis of experimental results to determine the values of parameters of 30 soil samples as input data including: moisture content, grain content passing sieve No.200, storm harmony, optimum humidity, plasticity index, liquid limit, flexural strength, deviator stress, lateral pressure and EMS value. Regression coefficient analysis program includes the following programs:

C.1 - Lemachieuall program performs calculation including the following steps: from the input data, calculation and determination of $\mathrm{k}_{1}$ by formula (5), (7); calculate the exponent base by formula (4); calculate and determine $\mathrm{k}_{2}$ by formula (6), (8); calculate $\mathrm{M}_{\mathrm{r}} / \mathrm{P}_{\mathrm{a}}$ value by formula (26); Output the values of the regression coefficients $a_{11}, a_{12}, a_{2}, a_{3}, a_{4}, a_{5}, a_{6}, a_{7}, a_{8}, a_{9}, a_{10} ; b_{11}, b_{12}$, $\mathrm{b}_{2}, \mathrm{~b}_{3}, \mathrm{~b}_{4}, \mathrm{~b}_{5}, \mathrm{~b}_{6}, \mathrm{~b}_{7}, \mathrm{~b}_{8}[32]$.

The Lemachieuall program includes subroutines:

C. 2 - Lemakk is used to determine $k_{1}$ and $k_{2}$, including the steps: calculating and determining $\mathrm{k}_{1}$ by formula (5), (7) in two cases where the lateral pressure is greater than 0 or the pressure not equal to 0 ; calculate the exponent base using Equation (26); $\mathrm{k}_{2}$ is calculated and determined by the formula (6), (8) in two cases where the lateral pressure is greater than 0 or the lateral pressure is 0 ; calculate $\mathrm{M}_{\mathrm{r}} / \mathrm{P}_{\mathrm{a}}$ value by formula (4); calculate the partial derivative $\mathrm{k}_{1}$; calculate the partial derivative $\mathrm{k}_{2}$; Output the results $\mathrm{k}_{1}$ and $\mathrm{k}_{2}$ values [32].

C.3 - Lemak1 Ai is used to determine the coefficients of an, including the following steps: calculating and determining $\mathrm{M}_{\mathrm{r}} / \mathrm{P}_{\mathrm{a}}$ value by formula (26); calculate the partial derivative for the coefficients $a_{11}, a_{12}, a_{2}, a_{3}, a_{4}, a_{5}$, $a_{6}, a_{7}, a_{8}, a_{9}, a_{10}$; Output the results of the values of the coefficients $a_{11}, a_{12}, a_{2}, a_{3}, a_{4}, a_{5}, a_{6}, a_{7}, a_{8}, a_{9}, a_{10}$ [32].

C.4 - Lemak2Bi is used to determine the $b_{n}$ coefficients including the following steps: calculating $\mathrm{M}_{\mathrm{r}} / \mathrm{P}_{\mathrm{a}}$ value 
according to formula (26); calculating the partial derivative for the coefficients $b_{11}, b_{12}, b_{2}, b_{3}, b_{4}, b_{5}, b_{6}, b_{7}$, $b_{8}$; Output the values of the coefficients $b_{11}, b_{12}, b_{2}, b_{3}, b_{4}$, $b_{5}, b_{6}, b_{7}, b_{8}$. (The results of coefficients $a_{n}$ and $b_{n}$ are shown in Table 5) [32].

Run the Lemakk program, select the values $\mathrm{k}_{1}$ and $\mathrm{k}_{2}$ with correlation coefficient $\mathrm{R}^{2}$ greater than or equal to 0.80 and the sum of squares SS less than or equal to 1 with lateral pressure greater than 0 , obtain Get the EMS values [32].

Using the Lemachieuall program with 1,351 iterative steps, for convergence results, the results obtained the values of the coefficients of soil $a_{n}$ and $b_{n}$ with correlation coefficient $\mathrm{R}^{2}$ equal to 0.8929 as shown in Table 4 [32].

Compare the proposed research coefficients with Kim. MS coefficients for soil type A-6 is shown in Table 6 .

Coefficients $a_{9}$ equal to - 0.072 (negative number) and $\mathrm{a}_{10}$ equal to 3,650 (positive number) are additionally determined to take into account the adverse effect of finer particles than $0.075 \mathrm{~mm}$ on the value of EMS, when humidity increases. The greater the fine particle percentage, the higher the percentage change of EMS value.

Table 5. $a_{n}$ and $b_{n}$ coefficients for sandy clay in the Mekong Delta

\begin{tabular}{|c|c|c|c|}
\hline Coefficient & $\mathbf{k}_{\mathbf{1}}$ & Coefficient & $\mathbf{k}_{\mathbf{2}}$ \\
\hline $\mathrm{a}_{11}$ & 2.007 & $\mathrm{~b}_{11}$ & 0.000007 \\
\hline $\mathrm{a}_{12}$ & 13.612 & $\mathrm{~b}_{12}$ & 0.000002 \\
\hline $\mathrm{a}_{2}$ & 0.945 & $\mathrm{~b}_{2}$ & 2.364 \\
\hline $\mathrm{a}_{3}$ & -101.047 & $\mathrm{~b}_{3}$ & 0.360 \\
\hline $\mathrm{a}_{4}$ & 19.444 & $\mathrm{~b}_{4}$ & 17.900 \\
\hline $\mathrm{a}_{5}$ & 1.044 & $\mathrm{~b}_{5}$ & 4.371 \\
\hline $\mathrm{a}_{6}$ & 6.951 & $\mathrm{~b}_{6}$ & -0.712 \\
\hline $\mathrm{a}_{7}$ & 3.996 & $\mathrm{~b}_{7}$ & -0.004 \\
\hline $\mathrm{a}_{8}$ & 17.776 & $\mathrm{~b}_{8}$ & -0.001 \\
\hline $\mathrm{a}_{9}$ & -0.072 & & \\
\hline $\mathrm{a}_{10}$ & 3.650 & & \\
\hline
\end{tabular}

Coefficients $\mathrm{a}_{12}$ equal to 13,612 and $\mathrm{a}_{8}$ equal to 17,776 are determined to be positive to consider the adverse effect when the humidity exceeds the optimum humidity $\mathrm{k}_{1}$ decreases, EMS decreases.

Coefficients $\mathrm{a}_{3}$ equal to -101.047 (negative numbers) and $\mathrm{a}_{4}$ equal to 19.444 (positive numbers) are relatively large in the correlation between the coefficients, considering the effect of saturation, saturation increases, EMS decreases.

Coefficient $\mathrm{a}_{5}$ equal to 1.044 is defined as a positive correlation, considering the effect of the compressive strength on the value of EMS, the compressive strength decreases, the EMS decreases.

Coefficient $\mathrm{a}_{6}$ equal to 6.951 is defined as a positive number with appropriate correlation, considering the effect of the plasticity index on the value of EMS, the plastic index increases, the EMS increases.

The coefficient $a_{7}$ is 3.996 is determined to be a positively correlated positive number, considering the effect of the difference between the liquid limit and the moisture content on the value of EMS, the closer the humidity increases to the liquid limit, EMS more and less.

The coefficients $\mathrm{a}_{11}$ equal to 2007 and $\mathrm{a}_{2}$ equal to 0.945 are positive numbers, which are well correlated considering the beneficial effect of lateral pressure on the value of EMS, increased lateral pressure, increased EMS.

Similarly, a factor $b_{12}$ of 0.000002 is defined as a positive number to consider the effect of the difference in humidity relative to the optimum humidity. The $b_{12}$ value is very small, has almost no effect on EMS.

The coefficients $b_{3}$ equal to 0.360 and $b_{4}$ equal to 17,900 are relatively large positive numbers in the correlation between the bn coefficients, considering the significant effect of saturation on EMS, increased saturation, and decreased EMS.

The coefficients $b_{5}$ equal to 4,371 (positive number) and b6 equal to $-0,712$ (negative number) are correlated accordingly, considering the effect of the compressive strength on the value of EMS, the decrease in compressive strength, EMS reduction.

The coefficient $b_{7}$ equal to -0.004 is defined as a negative number and has a suitable correlation considering the effect of the plasticity index on the value of EMS, the plasticity index increases, the EMS increases.

Coefficient $b_{8}$ equal to -0.001 is defined as a negative number and has a suitable correlation considering the influence of liquid limit on EMS.

The coefficients $b_{11}$ equal to 0.000007 and $b_{2}$ equal to 2.364 are positive numbers, which are well correlated considering the beneficial effect of lateral pressure on the value of EMS, increased lateral pressure, increased EMS. Comparing with the coefficients of Kim. MS, $a_{9}$ coefficient equal to -0.072 (negative number) and $\mathrm{a}_{10}$ equal to 3,650 (positive number) is added, demonstrating the adverse effect of the fine grain content smaller than $0.075 \mathrm{~mm}$ to the value of EMS, when humidity increases.

The coefficients $a_{11}$ and $a_{12}$ are found to be decreased, while $a_{2}$ is found to be increased, and the effect of lateral pressure on EMS is different; the coefficients $a_{3}$ and $a_{4}$ found to be increased, the effect of saturation on the EMS decreased; coefficient $a_{5}$ is found to increase, and the effect of compressive strength on EMS increases; the coefficient $a_{6}$ found increases, the effect of plasticity index on EMS increases; the coefficient $a_{7}$ found is reduced, the effect of the difference between the liquid limit and the moisture content on the EMS decreases; $\mathrm{a}_{8}$ coefficient found to be reduced, the effect when the humidity exceeds the optimum humidity on the EMS decrease; 
Table 6. Comparison of proposed coefficients with Kim.MS coefficients

\begin{tabular}{|c|c|c|c|c|c|}
\hline Coefficient & Propose & Kim.MS & Increase $(\%)$ & Reduce (\%) & Note \\
\hline a11 & 2,007 & 8,320 & 75,9 & & \\
\hline a12 & 13,612 & 71,960 & 81,1 & & \\
\hline $\mathrm{a} 2$ & 0,945 & 0,700 & & 35,0 & \\
\hline a3 & $-101,047$ & $-29,800$ & & 239,0 & \\
\hline $\mathrm{a} 4$ & 19,444 & 6,500 & & 199,1 & \\
\hline a5 & 1,044 & 0,886 & & 17,8 & \\
\hline a6 & 6,951 & 5,300 & & 31,2 & \\
\hline a7 & 3,996 & 4,800 & 16,7 & & \\
\hline a8 & 17,776 & 30,070 & 40,9 & & \\
\hline a9 & $-0,072$ & 0,000 & & & Additional \\
\hline a10 & 3,650 & 0,000 & & & Additional \\
\hline b11 & 0,000007 & 0,007530 & 99,9 & & \\
\hline b12 & 0,000002 & 0,002700 & 99,9 & & \\
\hline b2 & 2,364 & 0,523 & & 352,0 & \\
\hline b3 & 0,360 & 0,205 & & 75,7 & \\
\hline b4 & 17,900 & 13,400 & & 33,6 & \\
\hline b5 & 4,371 & 1,130 & & 286,8 & \\
\hline b6 & $-0,712$ & $-0,612$ & & 16,3 & \\
\hline b7 & $-0,004$ & $-0,0002$ & & $2.011,3$ & \\
\hline b8 & $-0,001$ & $-0,0002$ & & 211,0 & \\
\hline
\end{tabular}

The coefficients $b_{11}$ and $b_{12}$ are found to be reduced, $b_{2}$ found to be increased, the effect of lateral pressure on EMS is different; the coefficients $b_{3}$ and $b_{4}$ found to be increased, the effect of saturation on the EMS decreased; coefficients $b_{5}$ and $b_{6}$ are found to be increased, the effect of compressive strength on EMS increases; the coefficient $b_{7}$ is found to increase, the effect of compressive strength on EMS increases; the coefficient b8 found increases, the effect of the liquid limit on the EMS increases.

The regression coefficients an affect the EMS value a lot, for soil type A-6 (sandy clay), Kim. MS is considered to be finer particles than $0.075 \mathrm{~mm}$, does not affect EMS, the coefficient $a_{9}$ is equal to 0 and the coefficient $a_{10}$ is 0 . Therefore, if considering the effect of finer particles than $0.075 \mathrm{~mm}$ on the EMS value, the coefficient $\mathrm{a}_{9}$ is -0.072 and the coefficient $a_{10}$ is 3,650 . There must be a corresponding increase or decrease change.

The negative regression coefficients have an increase or decrease but have little effect on EMS value.

Values of coefficients $\mathrm{k}_{1}$ and $\mathrm{k}_{2}$ according to Lemachieuall program are compared with $\mathrm{k}_{1}$ and $\mathrm{k}_{2}$ according to Kim. MS for 63 cases. Correlation coefficient for $\mathrm{k}_{1}$ is 0.9850 ; for $\mathrm{k}_{2}$ it is 0.9836 .

The results of this study are consistent with the conclusions of previous studies, although the same type of sandy clay, for the Mekong Delta, EMS has a much smaller value than EMS of sandy clay in Ohio, USA [28].

\section{Evaluate the reliability of the coefficients:}

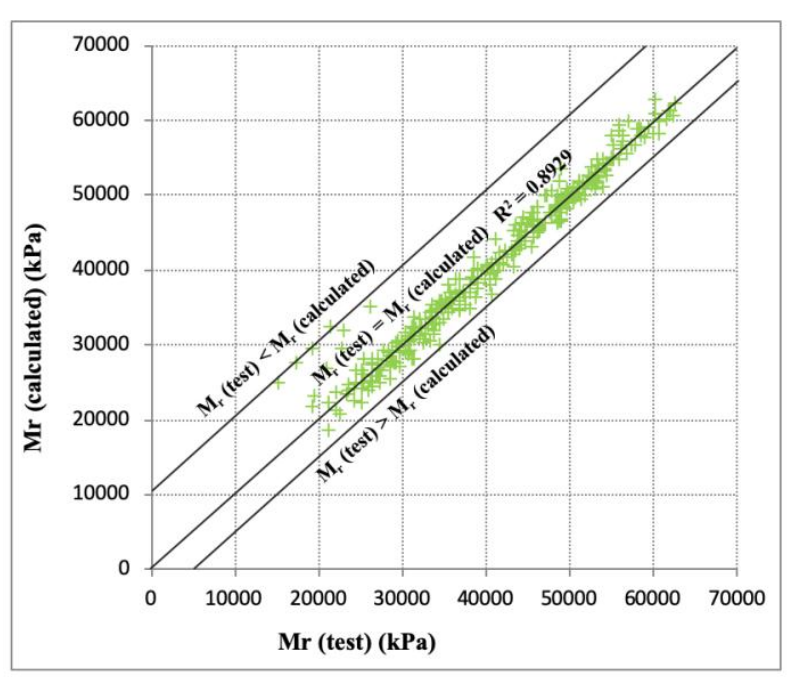

Figure 6. Correlation of the estimated $M_{r}$ value by coefficient $a_{n}$ and $b_{n}$, the results found with the results of the three-axis rapid compression test

To assess the reliability of the coefficients of $a_{n}$ and $b_{n}$ after conducting a regression analysis, it is necessary to consider the correlation coefficient between the EMS values of the experimental soil samples estimated by the formula (4), using the coefficients of $a_{n}$ and $b_{n}$ found by regression analysis by Levenberg - Marquardt algorithm (Table 5) with the results of rapid compression test using 
three-axis compression chamber on soil samples [26,27]. For each humidity, lateral pressure, deviator stress, the sample is estimated as $M_{r}$ value and compared with the results of rapid compression test of that sample. Comparisons are made with the test moisture values. The results of assessing the EMS correlation between estimating EMS value according to the proposed regression coefficients compared with the results of rapid compression test using three-axis compression chamber are quite suitable, with correlation coefficient $\mathrm{R}^{2}$ of 0.8929 acceptable as shown in Fig. 6 .

\section{Conclusions}

1) Due to improving the selection of adjustment coefficients by adding the coefficient $\mu$, the Levenberg-Marquardt algorithm has solved the problem with only 1,351 iterations, proving its simplicity and efficiency to solve the square problem. nonlinear minima that is sometimes not possible by the Gauss-Newton method. This algorithm is applied to regression analysis of experimental results, adding values of coefficients $\mathrm{a}_{9}$ and $\mathrm{a}_{10}$, proposing the values of the coefficients and the rest of the formula (26), with correlation coefficient $\mathrm{R}^{2}$ equal to 0.8929 , it is acceptable to apply the EMS value calculation of the sandy clay embankment in the Mekong Delta.

2) The results of regression analysis show that coefficients $a_{9}$ are and $a_{10}$ have been added to consider the adverse effects of the percentage of grain sizes smaller than $0.075 \mathrm{~mm}$ to the value of EMS. This result is consistent with the physical properties of sandy clay and overcome the limitation of formula (26). Comparing the differences of the research results with that of Kim. MS, the coefficients $a_{3}, a_{4}$, $a_{5}, a_{6}, b_{3}, b_{4}, b_{5}, b_{6}, b_{7}$ increase, indicate the degree of influence of the saturation, compressive strength and plasticity index of the soil to EMS more. And the coefficients $a_{11}, a_{12}, b_{11}, b_{12}$ decreased, indicating the degree of influence of lateral pressure on EMS is different. The coefficients $a_{7}, a_{8}$ decrease, $b_{8}$ increase, determine the effect of the difference between limit of liquid and moisture, between optimum humidity and humidity on EMS decrease.

3) The regression coefficients found are only suitable for estimating EMS value for soil type A-6 (sandy clay) used as the roadbed of the Mekong Delta. However, the application of the regression coefficients found to estimate the EMS value is very simple. In this case, we just need to know the value of the input parameters including moisture content, particle content of more than $0.075 \mathrm{~mm}$, saturation., optimum humidity, plasticity index, liquid limit, flexural strength, lateral pressure, deviator stress. These parameters can be obtained through four laboratory experiments: standard compaction,
Atterberg limit, particle composition analysis and compression. The results of estimating the EMS value by this method will save considerable time and cost compared to the field test using the Benkelman ring gauge, especially for long-distance roads.

\section{Recommendation}

1) The study results can be referenced to calculate deformation limitation and prevent landslide in the Mekong Delta during flooding. Designing the roadbed of the Mekong Delta region within slow-speed traffic vehicles, intersections, parking lots, etc.

2) It is necessary to continue to study and establish the formula for estimating the EMS value of the roadbeds of flooded Mekong Delta areas within the range of fast traffic vehicles, highways, national highways, etc. View Considering the effect of $\mathrm{pH}$ as well as the salt content on the deformation of the roadbed.

\section{REFERENCES}

[1] AASHTO T294-94, "Standard Method of Test for Resilent Modulus of Subgrade Soils and Untreated Base/Subbase Materials - SHRP Protocol P46," American Association of State Highway and Transportation Officials, Washington, D.C., 1995.

[2] AASHTO M145- 91, "The Classification of Soil-Aggregate Mixtures for Highway Construction Puroses," American Association of State Highway and Transportation Officials, Washington, D.C., 1998.

[3] AASHTO T294-03, "Standard Method of Test for Resilient Modulus of Subgrade Soils and Untreated Base/Subbase Materials - SHRP Protocol P46," American Association of State Highway and Transportation Officials, Washington, D.C., 2003.

[4] AASHTO T88-04, "Particle Size Analysis of Soils," American Association of State Highway and Transportation Officials, Washington, D.C., 2004.

[5] AASHTO T274-03, "Standard Method of Test for Resilient Modulus of Subgrade Soils," American Association of State Highway and Transportation Officials, Washington, D.C., 2003.

[6] Björck, A. "Numerical methods for least squares problems" SIAM, Philadelphia. ISBN 0-89871-360-9, 1996.

[7] Burczyk, J. M. et al, "Factors Influencing Determination of a Subgrade Resilient Modulus Value," Transportation Research Record No 1462, Transportation Research Board, National Research Council, pp. 72-78, 1994.

[8] Carmichael, R. F. III and Stuart, E., "Predicting Resilient Modulus: A Study to Determine the Mechanical Properties of Subgrade Soils," Transportation Research Record No 1043, 
Transportation Research Board, National Research Council, pp.145-148, 1986.

[9] Dong-Gyou Kim, M. S. "Development of a constitutive model for resilent modulus of cohesive soils", The Ohio State University, 2004.

[10] Drumm, E. C. et al, "Estimation of Subgrade Resilient Modulus from Standard Tests," Journal of Geotechnical Engineering, ASCE, Vol. 116, No. 5, May, pp. 774-789, 1990.

[11] Elliot, R. P., and Thornton, S. I. "'Simplification of subgrade resilient modulus testing," Transportation Research Record 1192, Transportation Research Board, National Research Council, Washington, DC, pp. 1-7, 1988.

[12] Erdem Çöleri, "Relationship between resilent modulus and soil index properties of unbound materials", Thesis, 2007.

[13] Fredlund, D. G. et al, "Relation between Resilient Modulus and Stress Research Conditions for Cohesive Subgrade Soils," Transportation Record No 642, Transportation Research Board, National Research Council, pp. 73-81, 1977.

[14] George, K., P. "Prediction of resilient modulus from soil properties index." University Mississippy, Nov, 2004.

[15] Henri P. Gavin (2019), The Levenberg-Marquardt algorithm for nonlinear least squares curve-fitting problems, Computer Science, IEEE Journal of Solid-State Circuits, 2019.

[16] Hicks, R. and Monismith C.L., "Factors influencing the Resilient Response of Granular Materials", Highway Research Record 345, Highway Research Record Board, Washington, D.C., 1971.

[17] Johnson, T., Berg R., and DiMillio A., "Frost Action Predictive Techniques: An Overview of Research Results", TRR 1089, TRB, Washington, D.C., 1986.

[18] Jose Pujol (2007). "The solution of nonlinear inverse problems and the Levenberg-Marquardt method".

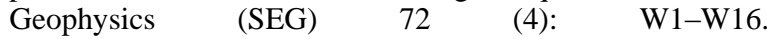
doi:10.1190/1.2732552.

[19] K. Madsen, H.B. Neilsen, O. Tingleff, "Methods for Non-linear least squares problems" 2nd edition, April 2014.

[20] Keyvan Amini,Faramarz Rostami \&Giuseppe Caristi, An efficient Levenberg-Marquardt method with a new LM parameter for systems of nonlinear equations, Optimization-A Journal of Mathematical Programming and Operations Research, 2018.

[21] Kim, D. S., Kweon, G. C., and Rhee, S, “Alternative method of determining resilient modulus of subbase soils using a static triaxial test," Canadian Geotechnical Journal, Vol.38, No. 1, pp. 117-124, 2001.
[22] Lee, W. J. et al, "Resilient Modulus of Cohesive Soils and the Effect of Freeze-Thaw," Canadian Geotechnical Journal, Vol. 32, pp. 559-568, 1995.

[23] Letcher, Roger. Practical methods of optimization (2nd ed.). New York: John Wiley \& Sons. ISBN 978-0-471-91547-8, 1987.

[24] Mark K. Transtrum and James P. Sethna "Improvements to the Levenberg-Marquardt algorithm for nonlinear least-squares minimization," Preprint submitted to Journal of Computational Physics, January 30, 2012.

[25] Masoud Ahookhosh Francisco J. Arag'on Artacho, Ronan M.T. Fleming Phan T. Vuong, Local convergence of the Levenberg-Marquardt method under $\mathrm{H}^{*}$ older metric subregularity, Advances in Computational Mathematics, 2019.

[26] Ministry of Transport, Standard 22TCN - 211- 06 "Soft dressing-Requirements and Design Instructions", Ha Noi, Viet Nam, 2006.

[27] Ministry of Science and Technology, Standard TCVN 4200-2012 "Soils - Laboratory methods for determination of compressibility”, Ha Noi, Viet Nam, 2012.

[28] Ohio Department of Transportation, Pavement Design Concepts, 1999.

[29] Pezo, R., "A General method of Reporting Resilient Modulus Tests of Soils, A Pavement Engineer's Point of View", 72nd Annual meeting of Transportation Research Board, Jan. 12-14, Washington, D.C., 1993.

[30] Santha, B.L., "Resilient Modulus of Subgrade Soils: Comparison of Two Constitutive Equations," Transportation Research Record No 1462, Transportation Research Board, National Research Council, pp. 79-90, 1994.

[31]Zhu, X., Lin, G.H.: Improved convergence results for a modified Levenberg-Marquardt method for nonlinear equations and applications in MPCC. Optim. Methods Softw. 31(4), 791-804 (2016).

[32] Chieu Quang Phan, Study on the effects of moisture and fine grain content on the elastic modulus of sandy clay embankment in the Mekong Delta, PhD. Thesis, Ho Chi Minh City University of Technology, 2018.

[33] Armand Augustin Fondjo, Elizabeth Theron , "Assessment of the Mineral Composition of Heaving Soils Using Geotechnical Properties," Civil Engineering and Architecture, Vol. 8, No. 4, pp. 619 - 631, 2020. DOI: 10.13189/cea.2020.080425.

[34] Tuan Anh Nguyen, Dat Thanh Nguyen, Tung Thanh Pham, Linh Truong Chau, "Study on Using Fly Ash for Fly Ash Soil Piles in Reinforcing Soft Ground," Civil Engineering and Architecture, Vol. 8, No. 5, pp. 1074 - 1085, 2020. DOI: 10.13189/cea.2020.080534. 